\title{
Indexed and Non-Indexed Insurance
}

\author{
by Yaffa Machnes *
}

\section{Introduction}

Inflation is usually defined as a substantial increase in the general level of prices or, alternatively, as a decrease in the purchasing power of money. Expectations of inflation cause people to believe that future prices of the various commodities will increase. As a result, the nominal interest rate on capital will rise until the return is sufficiently high to ensure the desired real rate. The double-digit inflation which has characterized much of the world's economy in the last decade has influenced all financial markets. It was to be expected that the insurance market would also be affected by inflation. By studying both the demand of the insured and the costs of insurers, one can come to conclusions about changes in the volume of insurance policies, the market price and the insurers' profits. This study will refer to nominal fixed sum insurance, such as life insurance, and also to insurance contracts that retain the real value, such as property, liability and health insurance. It will be shown that in all insurance fields, expectations of inflation will decrease the real volume of insurance and the profits of insurers.

This paper spells out the conditions for the existence of real (or indexed) insurance and the cases where both indexed and non-indexed policies will be sold in the same insurance branch. Our analysis will utilize models that are used in the economic theory of uncertainty and insurance (Arrow [1], Borch [2], Mossin [9] and Stiglitz [12]). The study of the bonds market under inflation is based on the ideas of Fisher [5] and Patinkin [10]. The introduction of indexed bonds will apply to the models presented by Fischer [4], Liviatan and Levhari [7].

\section{Life insurance}

Let $i$ denote the state of nature, $i=1,2.1$ is the state of nature that the insured person is alive and 2 is the state that he dies during the insurance period. $U_{i}$ is the

* Bar-Ilan University, Israel. I am grateful to a referee for important suggestions. Financial support received from the Wolfson Chair is gratefully acknowledged. 
utility function of the family who pays the premium and will benefit from the insurance in case of mortality. $W_{i}$ is the total wealth of the family including the present value of future income. In case the insured can keep the real value of his wealth along time, we have

$$
W_{2}=(1+r)\left(W_{1}-S\right)
$$

where $r$ is the real interest rate and $S$ is the consumption in the first period. $\pi$ denotes the probability of death. Let us assume that families maximize an additive utility function $G$ where

$$
G=(1-\pi) U_{1}\left(W_{1}-P C\right)+\pi U_{2}\left[W_{2}+C(1-P)\right]
$$

$C$ is the sum paid in case of death and $P$ the price of one dollar of insurance. It is assumed, for simplicity, that the premium is proportional to the amount of insurance. $P$ is based on the probability of death, the insurer expenses and the length of the insured period. It is always true that $P>\pi$ because the insurer has expenses and profits. To avoid multiple time dimension analysis we did not enlarge the expected utility equation to a two period model. $C$ represents the discounted value of the future payment. It is assumed that insureds are risk averse and $U_{i}$ fulfils $\frac{d U_{i}}{d W_{i}}>0$ and $\frac{d^{2} U_{i}}{d W_{i}^{2}}<0$

When inflation is expected, the purchasing power of the money that the beneficiaries will get in case of mortality declines.

The insurance policy covers a given period, a year for instance. Let us assume that if death happens, it occurs at the middle of that year. The general level of prices (or the Consumer Price Index - CPI) is expected to increase by $h$ during the following half year. The expected decrease in the purchasing power of the money is $1-f$.

$$
f=\frac{1}{1+h+\gamma V}
$$

$h$ measures the anticipated inflation, but there is also uncertainty about the value of the money in the future. Let $\gamma V$ denote the random element of future inflation. $\gamma$ is the random variable which fulfills $E_{\gamma}=0 . V$ measures the spread or variance of the unknown level of inflation in the future $V>0$.

When inflation is foreknown, the amount received in case of death will be $C f$. The family maximizes $F$ where

$$
F=(1-\pi) U_{1}\left(W_{1}-P C\right)+\pi \underset{\gamma}{E} U_{2}\left[W_{2}-P C+C f\right]
$$

Decrease of $f$ (when $P$ is given) is a deterioration of the terms of the insurance policy and is similar to an increase of $P$. The insureds can overcome the expected decrease of the compensation by increasing their chosen $C$, but it is expected that they will do the opposite thing. A decrease of $f$ by $\lambda$ is similar to an increase of $P$ by $\lambda$. The demand for insurance will decrease. 
In Figure 1 one can compare the demand curve $D_{0}$ which describes a case of no expectations for inflation to $D_{1}$, which was influenced by expected inflation. Both $D_{0}$ and $D_{1}$ depend on $W_{1}$ and $W_{2}$.

\section{Figure 1}

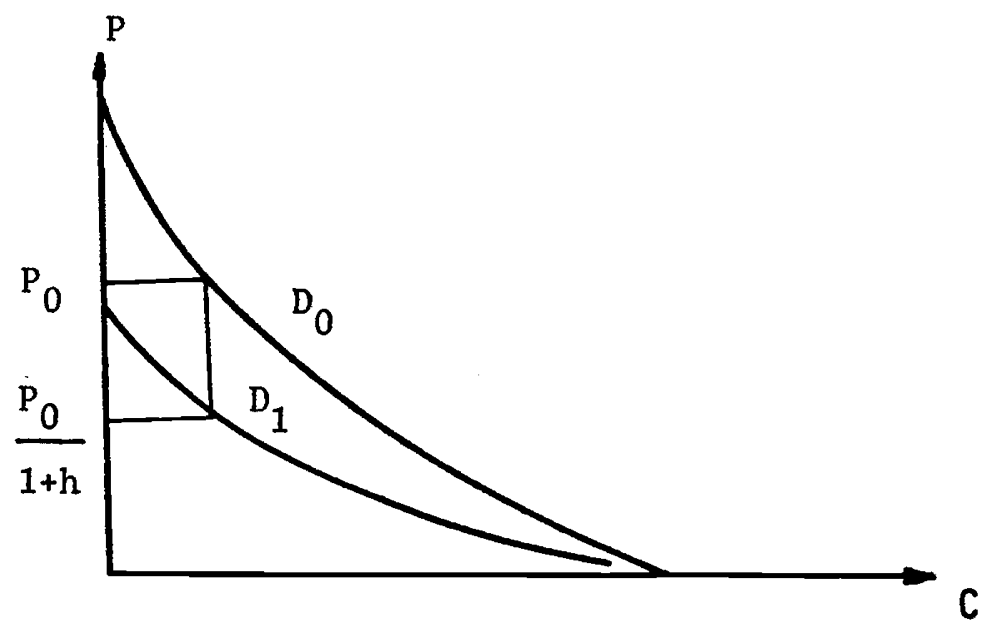

Formal presentation is shown in Appendix A.

Logue and Willett [8] and many other studies show that an increase of the rate of inflation is followed in most cases by an increase of the variance of its level.

Under the plausible assumption of disutility of negative asymmetric probability of loss we see that the demand for insurance decreases when the variance of insurance increases. In Figure 1, one can consider a further decline of $D_{1}$.

Let us now study the effect of inflation on the insurer.

Following Fisher [5], economists believe that nominal interest rate $m$ adjusts itself to the expected inflation. Patinkin [9] presents the equation

$$
1+m=(1+r)(1+h)
$$

where $r$ is the real interest rate. Assuming that nominal interest rate changes with expectations of inflation, the insurer will be able to preserve the real value of the premiums.

In case the insurer owns "old" bonds which he had bought before the inflation rate $h$ was expected, their value in the stock market declines when higher inflation is expected. Having as reserves "old" bonds will cause the insurer capital losses. Our analysis limits the discussion to the current insuring activities under expected inflation and excludes problems of capital gains or losses.

Let us denote by $n$ the number of life insurance policies sold with the amounts $C_{1}, C_{2}, \ldots, C_{n}$. 
Under inflation, the nominal expenses and profits of the insurer grow, but the amount paid to insureds is fixed and equal to $\pi \sum_{i=1}^{n} C_{i}$.

Let us first consider the simplest case : The future inflation is known $(V=0)$ and all the prices increase by $h$. In such a case the real total costs of the insurer will decrease by $\frac{h \pi}{1+h} \sum_{i=1}^{n} C_{i}$ and the marginal cost of one insured dollar by $\frac{h \pi}{1+h}$. The shift of the simplest fixed marginal cost is shown in Figure $2: M C_{0}$ will decline to $M C_{1}$. In case of uncertainty, the insurer does not know the future level of salaries and prices of his purchases, the decline of $M C_{0}$ will be smaller than $M C_{1}$. $\left(M C_{2}\right.$ for instance). The additional risk to the insurer about his future expenditures is equivalent to an additional administration cost denoted by $k$.

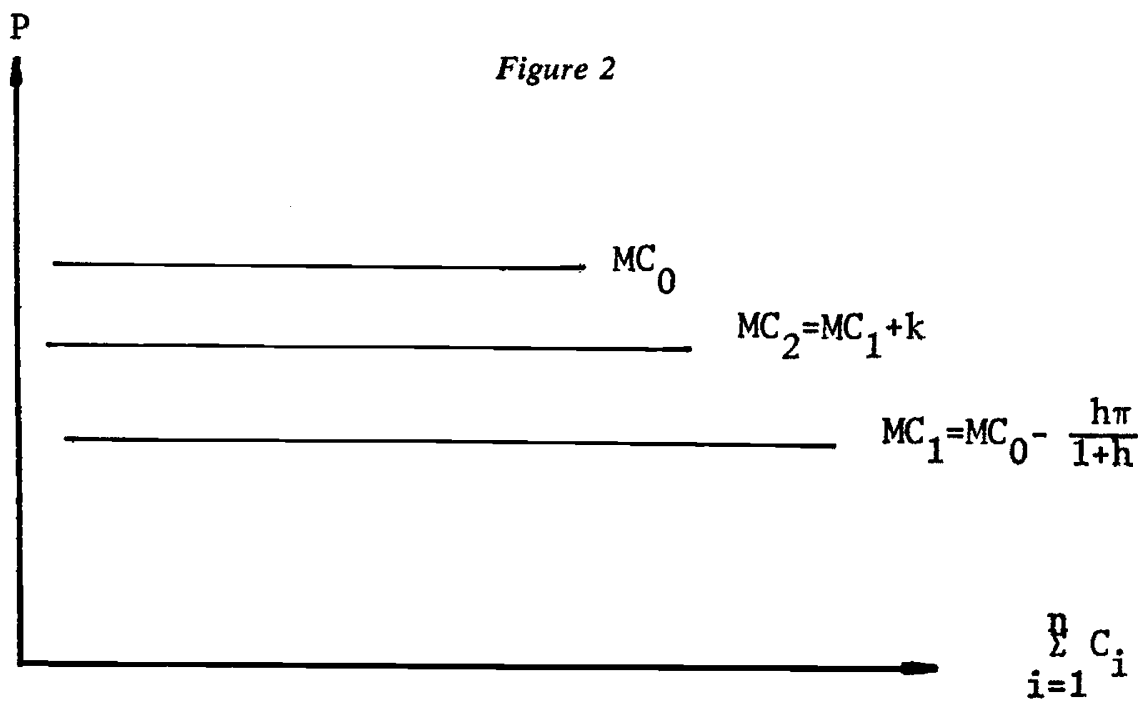

$k$ depends on the risk of future expenditures. The variance of future prices and the disutility from this additional risk impose extra costs on the insurers. The uncertain nominal payments are proportional to $(P-\pi) \sum_{i=1}^{n} C_{i}$ and the variance of the nominal payments depends on their variety : salaries, rent, profits to shareholders, etc. The more diverse these payments are, the smaller the risk to insurer, and the more homogeneous they are, the greater his risk.

In order to study the market equilibrium we first assume $V=0$, and later regard the more general case. We aggregate the demand of all insureds and construct the demand of the market. If $C_{i}(P)$ denotes the coverage demanded by insured $i$ at price $P$ then $\sum_{i=1}^{n} C_{i}(P)$ is the aggregate demand of $n$ insureds at the given price $P$. 


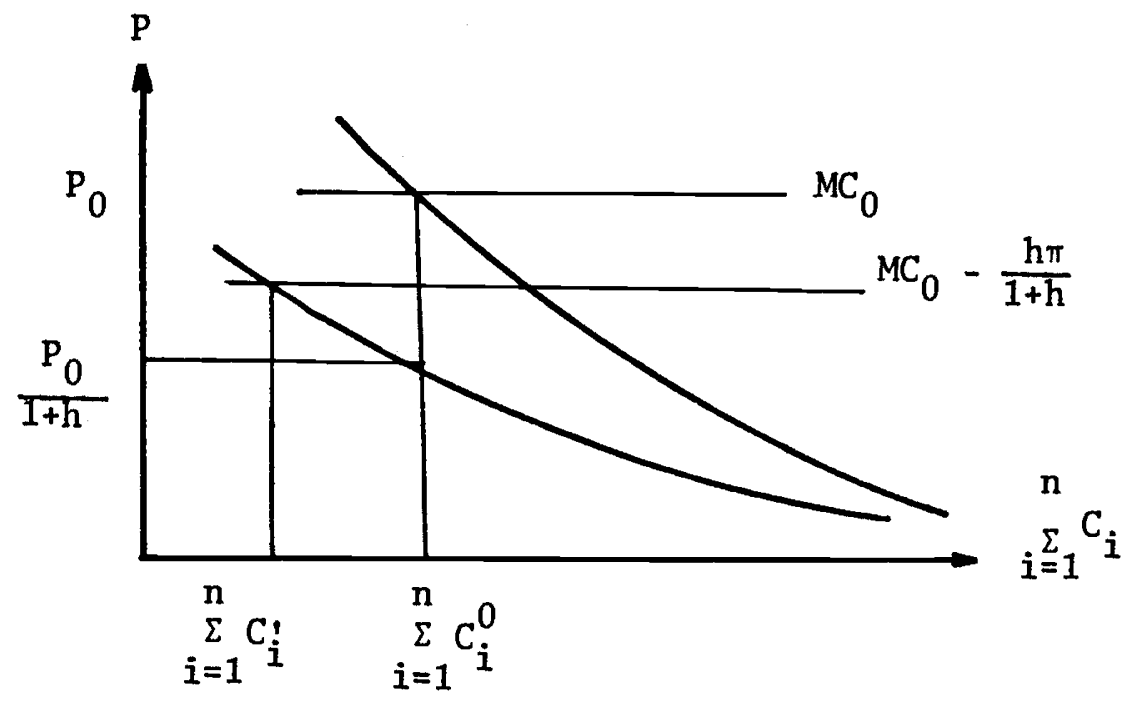

Figure 3

When no inflation is expected, the market price of insurance is $P_{0}$, and insureds buy the total coverage of $\sum_{i=1}^{n} C_{i}^{0}$. When inflation is expected, insureds are ready to buy $\sum_{i=1}^{n} C_{i}^{0}$ for the price $\frac{P_{0}}{1+h}$. The shift of the demand curve is shown in Figure 3.

Let us assume all insurers have similar marginal costs at the level $P_{0}$. The insurers' cost include normal profits which represent the return to the invested capital. In case there is competition in the market, the price $P_{0}$ is stable due to the power of demand and supply. Expected inflation of $h$ decreases expected cost of each insured dollar by $\frac{h \pi}{1+h}$. At the quantity $\sum_{i=1}^{n} C_{i}^{0}$, the decrease in demand is greater compared to the increase in supply. $P_{0}-\frac{P_{0}}{1+h}>\frac{h \pi}{1+h}$ as $P_{0}>\pi$. Insureds lose the purchasing power of the sum $P C_{i}$ but insurers gain the purchasing power only of the compensation $\pi C_{i}$. Thus, the market equilibrium price will be lower with less insurance coverage. Some insureds may decrease the optimal coverage to zero and leave the market. The insurers' rate of profit is constant but a decline of the quantity of insurance causes a decrease of the volume of profits. Thus, the profits of competitive insurers decrease as expected inflation increases.

Let us study the case of a monopoly which also includes a cartel. The monopoly insurer, who maximizes the profit, chooses to sell the quantity $\sum_{i=1}^{n} C_{i}^{*}$ at price $P^{*}$. The 
revenue is $R=P \sum_{i=1}^{n} C_{i}$ and the insurer chooses $\sum_{i=1}^{n} C_{i}^{*}$ so that the marginal cost equals the marginal revenue. The marginal revenue fulfills the equation

$$
M R=P\left(1-\frac{1}{\varepsilon}\right) \quad \varepsilon=-\frac{\Delta\left(\sum C_{i}\right) P}{\Delta P \sum_{i=1}^{n} C_{i}} \quad \varepsilon \text { is the demand elasticity. }
$$

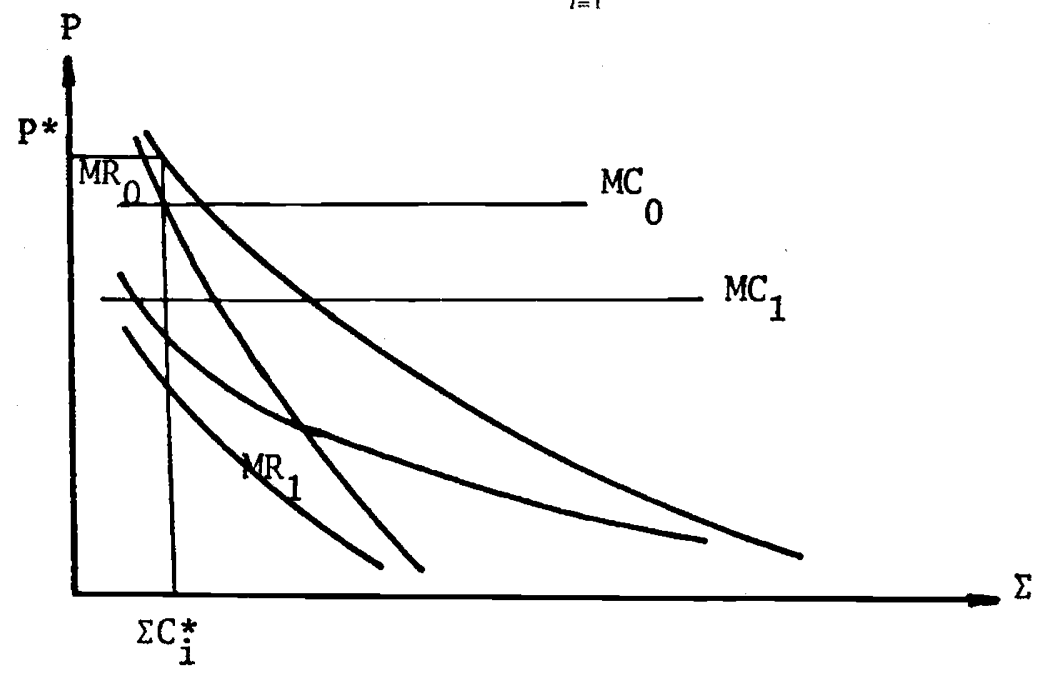

Figure 4

Figure 4 helps us to see the changes in the market. Under expected inflation, the demand shrinks by $\frac{h P}{1+h}$ as also do the revenue and the marginal revenue. $M R_{1}=\frac{1}{1+h} M R_{0}$. The marginal cost $M C_{0}$ declines by $\pi$. As both demand curve and marginal cost curve decline, the price of insurance decreases.

In order to establish whether the optimal quantity declines or not, we have to compare the decline of the marginal cost to the decline of the marginal revenue. $M C_{0}$ declines to $M C_{1} . M C_{1}=M C_{0}-\frac{\pi}{1+h}>\frac{M C_{0}}{1+h}$. The decline of the marginal revenue is greater than the decline of the marginal cost, and the optimal quantity decreases. The profits of a monopoly insurer decrease as expected inflation increases.

In the general case of positive $V$, our results will be even stronger, independent of the market structure. We get a further decrease of the insureds' demand and the marginal revenue. The effect of uncertainty on insurers is equivalent to an increase of the marginal costs. These additional shifts of the demand and the marginal costs cause a decrease of the optimal quantity and the profits of insurers. 


\section{Property, liability and health insurance}

In this section we refer to property insurance as it operates in the U.S.A. The insurer compensates insureds according to the real value of the loss independent of the nominal sum of money he has to pay.

The European insurers estimate the nominal value of property when the policy is written, and in case of loss or damage they pay only according to its nominal value at time of insurance underwriting. The effect of inflation on property insurance of the European style is similar to its effect on the life insurance market. In cases where self-protection is a good substitute for insurance, the decline of profits of European insurers is even greater. Investment in alarms, locks, etc., keeps the property at its real value and has the additional advantage in case of inflation. Formal presentation of this argument can utilize the model presented by Erlich and Becker [3].

Let us study the market for insurance policies that are not based on nominal value, and insurers compensate according to the nominal loss at time of its occurrence. First let us refer to policies with full insurance or proportional co-insurance. The insurer compensates according to a fixed fraction of the damage. Cases of fixed sum deductibles will be discussed later. In the following insurance fields : property, liability and health, the insureds get compensation in real terms and don't bother about the expected decline of the purchasing power of the money or of the necessity of the insurer to spend more money in nominal terms to compensate them. Thus, expectation of inflation does not influence the demand in these insurance fields.

By compensating the insureds according to the real value of the damage, the insurer pools many risks with a dependent variable.

Let $h$ denote the anticipated rate of inflation and $\eta Z$ the unexpected increase of prices. $\eta$ is a random variable so that $E_{\eta}=0$ and $Z>0$. We denote the payments to $n$ insureds by $C_{1}, \ldots, C_{n} . C_{1}, \ldots, C_{n}$ are statistically independent random variables, but the nominal future payment $C_{1}(1+h+\eta Z), \ldots, C_{n}(1+h+\eta Z)$ have a common component $1+h+\eta Z$.

The total nominal payments to insureds will be $(1+h+\eta Z) \sum_{i=1}^{n} C_{i}$. The average real payment to insureds is $\frac{1}{n} \sum_{i=1}^{n}\left(\frac{1+h+\eta Z}{1+h}\right) C_{i}$. On the assumptions $E C_{i}=E C$, $\operatorname{Var} C_{i}=\operatorname{Var} C$ its variance is

$$
\left(\frac{Z}{1+h}\right)^{2} \operatorname{Var}\left(\eta\left[\frac{\operatorname{Var} C}{n}+(E C)^{2}\right]\right)+\frac{\operatorname{Var} C}{n}
$$

We see that the risk of unanticipated inflation does not disappear by pooling, and it is transferred from the insureds to the insurer. Probably, the insurer is risk averse and will not be indifferent to the uncertainty he bears. The insurer takes on the risk of unknown future prices of insured items, such as property, medical care, etc., in addition to unknown prices of his various expenses. This risk concerns the whole sum 
of the insurer liabilities and threatens his profitability. The more diverse the insurance fields of the insurer are, the smaller is the uncertainty the insurer bears. Even in the ideal case in which the structure of the insurer's payments is identical to the bundle of the Consumer Price Index, the interest he will get on his assets is based on $h$ only and leaves to the insurer the uncertainty of the future price level. This uncertainty is equivalent to an additional cost which depends on the various future payments and the attitude of the insurer towards risk. This risk is proportional to future outlays and there are no benefits to scale. We see that insurers' marginal costs increase due to unanticipated inflation. The increase of marginal costs will increase price equilibrium and decrease both quantity and insurers' profits.

Introducing fixed deductibles into insurance policies does not change our results. Inflation would increase the probability of damages which are greater than the fixed nominal deductible written in the policy. Both the insureds and the insurer have expectations of inflation, and probably the deductible would be raised by $1+h$, at least. This change will save administrative expenses for settlement of relatively small claims. The uncertainty of future inflation will affect the market in two alternative ways : a) The insurer will raise the deductibles by more than $1+h$. The insureds will decrease their demand because the conditions of the policy worsened; $b$ ) The deductibles will be raised by less than $1+h$. The insurer will then bear the risk of having more small claims to settle. This risk will increase marginal cost and price. Both solutions, a) or b) will cause the decrease of profits. Thus, we see that the existence of deductibles in the policy may cause further decline of profits

\section{Indexed insurance}

We see that expectations for inflation will decrease the volume of insurance and the profits of insurers. This influence will occur either in the nominal life insurance field or in the fields of "real" insurance : property liability and health insurance. Now the question arises : which system is better for insurers? Would it be better to offer life insurance policies linked to Consumer Price Index, or should insurers change property insurance contracts to a nominal basis insurance like the European style of property insurance? The answer to this question can be found in the models presented in the former chapters.

The demand for indexed (or real) insurance is higher by $(1+h) P$ plus some risk aversion premium. The major costs to the insurer are higher by $(1+h) \pi$ plus his risk of unexpected inflation. Insurers compare the additional revenue $\sum_{i=1}^{n}(P-\pi) h C_{i}$ plus the insureds' risk aversion premiums to their additional risk. The risk to insurer concerns the whole sum of money he pays to insureds. Formal presentation of this proposition can be found in Appendix B. By comparing the increase of demand to the increase of insurers' costs we can assess whether or not price linked insurance will be sold. Although we do not have data of the expected.inflation $h$ and the risk aversion of insureds and insurers, we can explain the existence or non-existence of indexed insurance by these indications. 
Life insurance is a contract for a long period with relatively low expenses. The fraction $\frac{P}{\pi}$ is relatively small, and the variance of future inflation is high because the insurance period is long. Insurers who might offer indexed insurance take upon themselves a large risk for relatively low additional payment. Because of this, we don't find such indexed life policies.

Property, liability and health insurance policies retain the real value because the conditions in these markets are different. The ratio $\frac{P}{\pi}$ is higher because of greater expenses. The insurance period is relatively short, and by insuring the real value of the loss, the insurer does not bear a risk. It can be expected that if the uncertainty about future price level were to increase, insurers would change the insurance contracts to a nominal basis in order to prevent additional risk.

In an economy with indexed bonds, as described by Fischer [4], Liviatan and Levhari [7], life insurance contracts are sold. Insurers who are offered bonds linked to the Consumer Price Index can offer indexed insurance without bearing the risk of unknown inflation. They still have the risk of the deviation between the price level of their own expenses from that of the C.P.I. Liviatan and Levhari [7] show that only the government can establish a market for indexed bonds, otherwise that market could not exist. By selling indexed bonds to insurers, the government helps the insurance market to overcome the negative influence of inflation. Protecting the insurance market would increase the consumers' welfare without real cost to the government. The government is then able to pool inflationary risks over time without any added cost to the economy. Such interference would improve the welfare of insureds by decreasing their uncertainty.

It is interesting to find under which conditions there would be markets for both indexed and non-indexed insurance contracts in the same insurance field. In the case in which all insurers and insureds have similar expectations concerning future rate of inflation, the indexed insurance would dominate the non-linked insurance. The non-indexed insurance policies would disappear from the market. The dominance of linked insurance is independent of market structure : competition or monopoly. In the case of competition, the difference in the costs between indexed and non-indexed insurance is $\frac{h}{P}(P-\pi)$. The difference is smaller than $h$ because, in the event that the policy is not indexed, the expenses and profits of the insurer also increase due to inflation. Insureds who can choose between paying $P+h P$ for indexed insurance and $P+h(P-\pi)$ for non-indexed insurance, would choose indexed insurance. A monopoly can sell both indexed and non-indexed insurance. In case the differences in prices between indexed and non-indexed policies are smaller or equal to $h P$, all consumers (who have similar expectations of inflation) would prefer indexed insurance. When the difference is greater than $h P+\lambda$ consumers would choose their desired insurance by comparing $\lambda$ to their risk aversion premium. By buying indexed insurance, insureds prevent the risk of unexpected inflation. By fixing a difference greater than $h P$, the 
monopoly sells non-indexed insurance cheaper than indexed insurance. Even if the lower price of non-indexed insurance covers the marginal expenditure of the insurer, it decreases his profit. The suggested "discrimination" between consumers according to their attitude towards risk is equivalent to a decrease of price. The cheaper nonindexed alternative would increase the sold quantity, but would also cause consumers to transfer from expensive indexed insurance to the cheaper non-indexed insurance. The difference in costs to the insurer is smaller than the difference in price to insureds. Since in the optimal quantity the demand for insurance is inelastic, the additional quantity that would be sold due to the introduction of cheap, non-indexed insurance, would decrease profits.

In case different consumers vary in their expectations concerning future inflation $h$, there is ground for non-indexed insurance. Insureds who face a price $P_{0}$ for indexed insurance and expect the inflation to be $h_{0}$, would buy non-indexed insurance only if it is cheaper than $\frac{P_{0}}{1+h_{0}}$. For example, in case $P-\pi=\frac{P}{3}$ and insurers expect the inflation in the next half year to be such that $h=0.06$, they would sell non-indexed insurance at price 0.96 of the indexed one. Only an insured who believes $h_{0}<0.04$ would buy non-indexed insurance.

In case the expected inflation is not pure, and the prices of various assets do not increase at the same rate, insurers would prefer to sell insurance linked to the C.P.I. only if they can buy bonds which are linked to the C.P.I. Consumers prefer insurance which is linked to the price of the insured asset. Insurers, active in several branches, pool the uncertain risks concerning the future prices. By entering the stock market, the future and the forward markets, insurers can decrease their inflationary risks. The risk which is left to the insurer would be reflected in the price of insurance linked to the price of a specific asset.

\section{Conclusion}

Our paper proves that inflation hurts insurance market even in case that inflation is fully anticipated. Insurers have higher costs while insureds receive payments with smaller real value. As a result insurers have smaller profits and insureds suffer a loss of welfare. The longer is the period of insurance contract, the higher is the expected rate of inflation and thus the greater is the damage. Life insurance is hurt more than other fields and as a result responds faster than other fields to the hazards caused by inflation.

In order to protect the insurance market against inflation, it is suggested to link both the premiums and the payments to the price index. It is shown that indexation is possible only in case that insurers can buy indexed bonds for their reserves. Bonds linked to the consumer price index are sold only by government. By introducing these bonds and selling them to insurers, the governments can protect the insurance market from the inflation hazards. 


\section{Appendix A}

$F=(1-\pi) U_{1}\left(W_{1}-P C\right)+\underset{\gamma}{E} U_{2}\left[W_{2}+\frac{C}{1+h+\gamma V}-P C\right]$

$\frac{\partial F}{\partial C}=-(1-\pi) P U_{1}^{\prime}\left(W_{1}-P C\right)+\pi \underset{\gamma}{ }\left(\frac{1}{1+h+\gamma V}-P\right) U_{2}^{\prime}\left[W_{2}+\frac{C}{1+h+\gamma V}-P C\right]$

$\frac{\partial^{2} F}{\partial C^{2}}=\quad(1-\pi) P^{2} U_{1}^{\prime \prime}\left(W_{1}-P C\right)+\pi E_{\gamma}\left(\frac{1}{1+h+\gamma V}-P\right)^{2} U_{2}^{\prime \prime}\left[W_{2}+\frac{C}{1+h+\gamma V}-P C\right]$

Optimal $C$ will be found by solving the equation $\frac{\partial F}{\partial C}=0$.

Due to risk aversion $U_{1}^{\prime \prime}$ and $U_{2}^{\prime \prime}$ are negative, so the second derivate is negative which guarantees the maximum solution.

Let us assume that $P$ is given and calculate $\frac{d c}{d h}$. This relationship can be found by equating the first derivate to zero and calculating the full differential.

For $\frac{d c}{d h}<0$ it is required that

$$
\frac{C E\left[(1+h+\gamma V)^{-1}-P\right](1+h+\gamma V)^{-2} U_{2}^{\prime \prime}()}{E\left[(1+h+\gamma V)^{-1}-P\right](1+h+\gamma V)^{-2} U_{2}^{\prime}()}<1 .
$$

In case $V=0$ we get $\frac{C U_{2}^{\prime \prime}()}{U_{2}^{\prime}()}<1$.

This inequality of the value of the relative risk aversion premium is known in the literature and was presented by Stiglitz [12].

Uncertainty of future inflation can be presented in various ways. Following the simplest models (Samdo [11] for instance) we measure the uncertainty by an additive factor. Increasing $V$ means increasing variance of the level of prices in the future. Let us calculate $\frac{d C}{d V}$.

$\frac{d c}{d V}=\frac{\pi E \gamma(1+h+\gamma V)^{-2}\left[(1+h+\gamma V)^{-1}-P\right]\left[U_{2}^{\prime}()+C U_{2}^{\prime \prime}()\right]}{\frac{d^{2} F}{d c^{2}}}$

and $\frac{d c}{d V}<0$ under the assumption $U_{2}^{\prime \prime \prime}>0$. 
A positive third derivative of the utility function reflects the disutility of the negative asymmetry of the probability distribution of loss. People with positive third derivative of $U$ who have to choose between two random incomes with the same expected value and the same variance would prefer the one with the greater third moment. Positive third derivative of the utility function was assumed in several articles (Leland [6], Stiglitz [12]) and is a weaker assumption than decreasing risk aversion premium.

\section{Appendix B}

Let $U_{2 j}$ be the utility function of the beneficiaries of insured $j$ in case of his death. $U_{f}$ is the utility function of the insurer and $W_{f}$ his wealth.

The condition for preferring indexed or real insurance to a nominal one is

$$
\sum_{j=1}^{n}\left\{h(P-\pi) C_{j}-\frac{Z^{2} \operatorname{Var}\left(\eta C_{j}\right) U_{2 i}^{\prime \prime}\left[W_{2}+(1+h) C_{j}\right]}{2}\right\}>\frac{Z^{2} \operatorname{Var}\left(\eta \sum c_{j}\right) U_{f}^{\prime \prime}\left(W_{j}\right)}{2}
$$

When this inequality holds, the compensation paid by insureds is higher than the risk aversion insurers are ready to pay in order to eliminate the additional risk transferred to them.

\section{REFERENCES}

1. ARROW, K. J. : “Uncertainty and the welfare economics of medical care", American Economic Review, 53 (December 1963), 941-973.

2. BORCH, K. : “Equilibrium in a reinsurance market", Econometrica, 30 (July 1962), 424-444.

3. EHRLICH, I., and BECKER, G. : "Market insurance, self insurance and self protection", Journal of Political Economy, 80 (July 1972), 623-648.

4. FISCHER, S.: “The demand for indexed bonds", Journal of Political Economy, 83 (June 1975), 509-534.

5. FISCHER, I. : The Rate of Interest, Macmillan, New York, 1907.

6. LELAND, H. E. : "Savings and uncertainty. The precautionary demand of savings", Quarterly Journal of Economics, 82 (August 1968), 465-472.

7. LIVIATAN, N., and LEVHARI, D. : "Risk and the theory of indexed bonds", American Economic Review, 67 (June 1977), 366-375.

8. LOGUE, D., and WILLET, T.: "A note on the relationship between the rate and variability of inflation ", Economica, 42 (May 1976).

9. MOSSIN, J. : “Aspects of rational insurance purchasing”, Journal of Political Economy, 76 (July 1968), 768-783.

10. PATINKIN, D. : "Secular price movements and the economic development: Some theoretical aspects", in The Challenge of Development, A. Bonne (Ed.), The Hebrew University, Jerusalem, 1958.

11. SANDMO, A.: “On the theory of the competitive firm under price uncertainty", American Economic Review, 61 (March 1971), 65-73.

12. STIGLITZ, J.E.: "The effects of wealth, income and capital gains taxation on risk taking ", Quarterly Journal of Economics, 83 (May 1969), 263-283. 